\title{
MISCELÁNEA
}

\section{LA "VIDA Y HECHOS DE ESTEBANILLO GONZÁLEZ", ESPEJO DE LA LENGUA ESPAÑOLA EN FLANDES}

Es sabido que la Vida y hechos de Estebanillo González, novela picaresca de autor anónimo, publicada por primera vez en Amberes en 1646, es en gran parte autobiográfica. Los episodios relatados están contados por el propio protagonista, se han identificado casi todos los sitios de su itinerario a través de Europa y se ha logrado comprobar la identidad de muchos de los personajes con quien trata. Incluso se han podido fechar con gran aproximación casi todos los episodios de la novela.

Los capítulos VII, VIII y IX del Estebanillo se refieren casi en su totalidad $^{1}$ a su existencia en Flandes ${ }^{2}$. Se ha podido comprobar que se corresponden con un período que va desde 1635 (año en que Estebanillo González llega por primera vez a los Países Bajos españoles, procedente de Alemania donde presenció la famosa batalla de Nördlingen) hasta 1641 (año en que muere su protector, el Cardenal Infante Don Fernando, Gobernador general de los Estados de Flandes). En el último capítulo del libro (el XIII) ${ }^{3}$, encontramos de nuevo a Estebanillo en Bruselas.

1 Con excepción de algunos viajes a Austria.

2 Empleamos «Flandes» en el sentido amplio de la palabra, o sea, como equivalente de las diecisiete provincias de los «Países Bajos», al uso de los españoles de aquella época. De la misma manera utilizaremos el término de «flamencos» para referirnos a todos los habitantes - tanto los de habla neerlandesa como francesa (picarda, valona) - de los Países Bajos.

3 Entre 1642 y 1645 (Capítulos X, XI y XII) las estancias de Estebanillo González en Flandes son sólo ocasionales. 
Es allí donde, a comienzos de 1646, empieza a escribir su autobiografía, según dice, para allegar fondos con vistas a su retiro en Nápoles. Algunos meses después, su libro ya está terminado. El 28 de junio, recibe la "Suma del Privilegio» para su publicación y, poco después, el libro sale en Amberes, de la Imprenta de la viuda de Juan Cnobbart.

Ahora bien, no es la autobiografía de Estebanillo la que nos va a interesar aquí, sino el aspecto lexicológico de su obra. Efectivamente, la lengua de esta novela picaresca plantea una serie de problemas a veces arduos. Contiene toda una serie de voces técnicas, giros populares, germanía, arcaísmos y extranjerismos. Nuestro propósito es analizar sólo estos últimos, y particularmente los galicismos.

Las recientes ediciones críticas del Estebanillo ${ }^{4}$ mencionan la presencia de varios galicismos desconocidos en el español peninsular del siglo XVII, como por ejemplo ${ }^{5}$ :

ANTEPRESA: castellanización del fr. entreprise, con la acepción de «operación militar», que esta voz francesa tuvo entre el siglo xIv y el siglo XvIr.

"(..) y echandolos fuera, hazian tal guardia y ronda toda la noche, que qualquiera persona forastera, que llegasse ignorante de tales centinelas, lo hazian dos mil pedaços, con que estava assegurada de qualquier antepresa, y de qualquiera cautela enemiga (...)» (pág. 119).

BRANDEVIN, BRANDAVIN: castellanización del fr. brandevin, que se había tomado del nl. brandewijn, «aguardiente».

«(...) levantè el jarro, $i$ chupando gotas por hazer detencion, $i$ quitar sospechas, me estuve gran rato tragando mas ayre que brandevin (...)» (página 298).

«Ganava cada dia dos reales: y pareciendome poco, por ser mucho el gasto, me iva à los baxeles de la dicha armada todas las mañanas, y en ello trocava brandavin por vizcocho, y à vezes por polvora y balas (...)» (página 84).

CARAMESA: castellanización del fr. car(e)messe (hoy kermesse) que se habia tomado del medio nl. carmesse o kermesse.

«Era vna alegre fiesta de caramesa, el vernos, quan bien logravamos los ratos desocupados que teniamos, porque como el vino no nos avia costado nada, beviamos todos à discrecion (...)" (pág. 377).

4 Juan Millé y Giménez (Madrid, Espasa-Calpe, 2." reimpresión, 1968 [Clás. Cast., 108, 109]); Antonio Carreira y Jesús Antonio Cid (Madrid, Narcea, 1971 [Bitácora, 19]); Nicholas Spadaccini y Anthony N. Zahareas (Madrid, Castalia, 1978 [Clásicos Castalia, 86, 87]).

5 Citamos según la edición princeps (Amberes, Cnobbart, 1646), que es la única en que participó directamente el autor. 
LIARTE: castellanización del fr. liard, una antigua moneda de cobre. “(...) me sacaron à la calle, diziendo à grandes vozes, Palos à mi por un par de ravanos, valiendo à liarte el manojo» (pág. 198).

MALTOTA: castellanización del fr. maltôte, que designaba antiguamente un impuesto extraordinario.

«(...) quise ver si en aquel trinquete avia avido alguna falta: però hallandome sano i salvo, i libre de toda maltota i gavela, empecè poco à poco à tomar respiracion» (pág. 209).

MATRESA, METRESA: castellanización del fr. maîtresse, "amante».

"(...) estando yo un invierno de guarnicion en la villa de Gueldres, tuve una pendencia con un soldado de nacion Albanes, sobre cierta matresa (...)m (página 67).

“(...) pues obligados los estrangeros de la cortesia i affabilidad que hallan en sus metresas, $\mathrm{i}$ del amor que todo lo vence, llega una pobre doncella en virtud del casamiento à ser madamisela, $i$ infinidad dellas à madamas» (página 330).

RANÇION, RANÇON: castellanización del fr. rançon, "rescate».

«Dieronme por carcel una taberna, que era lo que la mona queria. Passò la fama, que era un vivandero rico, por loqual esperavan de mi una gran rançion (...)» (pág. 180).

«Dixome el Duque, Con esa pitima aliento tendra agora para tratar de su rançon» (pág. 181).

Los editores antedichos del Estebanillo no proporcionan ninguna explicación global sobre la presencia de éstos y otros muchos galicismos, con excepción de N. Spadaccini y A. N. Zahareas, que en la introducción de su edición dicen: "Originalmente el libro fue destinado a un público hispano-francés durante la guerra de los Treinta años $\mathrm{y}$, por eso, ofrece toda variedad de vacilaciones gráficas y una gran riqueza de peculiaridades culturales y fonéticas ${ }^{6}$ y luego, en una nota, puntualizan: «Recuérdese que Estebanillo escribía su libro en Bruselas para un público hispano-francés de señores y soldados que conocían bastante ambos idiomas" ${ }^{7}$.

De esto se podría deducir que, según Spadaccini y Zahareas, los numerosos galicismos en el Estebanillo no provocaban problemas de comprensión a los españoles de Flandes, porque estos lectores conocían el francés. No compartimos esta opinión, pues a lo largo de nuestras investigaciones en la lengua española de Flandes - que nos han obligado a consultar numerosos documentos inéditos de la época- hemos lle-

\footnotetext{
6 Op. cit., pág. 75.

7 Op. cit., nota 603 .
} 
gado a la convicción de que eran más bien los autóctonos - o sea los flamencos ${ }^{8}$ - los que aprendían el español, y no tanto los españoles las lenguas locales. La razón es bien sencilla: en los Países Bajos españoles había una ley de necesidad que hacía que los flamencos que desempeñaban altos cargos en la vida política y militar, aprendieran, hablaran y escribieran la lengua de los que tenían entonces el dominio de su territorio 9 .

Podría objetarse esta interpretación alegando que los españoles que vivían en Flandes entendían estos vocablos extranjerizantes que hay en el Estebanillo. Por supuesto que los entendían, pero no por conocer el francés, sino porque eran vocablos corrientes ${ }^{10}$ en la lengua española que se hablaba en Flandes ${ }^{11}$. Eso lo hemos podido comprobar al examinar un extenso corpus de escritos políticos y militares redactados entre 1567 (fecha de la llegada del Duque de Alba y de sus tercios a Bruselas) y 1646 (fecha de aparición del Estebanillo), textos redactados por oficiales y generales del Ejército español de Flandes, por ejemplo: Bernardino de Mendoza, Francisco Verdugo, Alonso Vázquez, Diego de Villalobos, Antonio Carnero, Carlos Coloma, el Marqués de Castel Rodrigo, etc. ${ }^{12}$. Estos extranjerismos los encontramos también en textos políticos y religiosos, escritos por españoles que residían en Flandes en aquella época. Varios de ellos, incluso los hemos hallado atestiguados en los diccionarios españoles de H. Hornkens, J. F. Rodríguez, A. de la Porte y F. Sobrino, que se publicaron en Bruselas y en Amberes en el siglo XVII ${ }^{13}$.

8 Véase la nota 2.

9 Véase nuestro libro La lengua española en Flandes en el siglo XVII. Contribución al estudio de las interferencias léxicas y de su proyección en el español general, prólogo de A. Zamora Vicente, Madrid, Insula, 1980, y más particularmente las páginas 21-29, 197-199 y 217-230.

10 Antepresa es una variante de entrepresa «operación militar» que hemos encontrado frecuentemente en nuestro corpus de textos españoles escritos en Flandes. Remitimos a las págs. 89-96 de La lengua española en Flandes...

11 Con excepción, por supuesto, de unos pocos casos donde el autor españoliza intencionadamente voces o expresiones francesas, por ej.: «(...) nos bevimos teta a teta media dozena de potes de cerveza» (pág. 68; < fr. tête à tête); «Marchámos por el Delfinado, haciẽdo buena chera, y en cada transito avia avenidas de brindis, al tenor de $A b u$ Monsieur de la fortuna, $A b u$ Monsieur de la esperanza” (pág. 125; $<$ fr. faire bonne chère; < fr. A vous); «Enfadavame ya de oyr tanto, allon, allon" (pág. 127; < fr. Allons, allons) o las transcribe como tales, por ej.: «Señor Estevanillo, que vuesa merced se vaya, o se buelva, que se quede $d$ no, pour moy es tout un" (pág. 263).

12 Ibid., págs. 231-233.

13 Véase nuestro artículo «Contribución al estudio de la lexicografía española en Flandes en el siglo XVII (1599-1705)», en Boletín de la Real Academia Española, tomo LIX, págs. 289-369. 
Por otra parte, estimamos que el término "préstamos» conviene más que el de "extranjerismos", ya que estos vocablos llegaron a constituir una parte integrante del patrimonio léxico de muchos de los españoles que vivían en Flandes, y de los flamencos que hablaban el español. Nuestra investigación nos permitió descubrir en el Estebanillo una riqueza mucho más variada de estos "préstamos", que los editores más recientes pasaron por alto. Por ejemplo ${ }^{14}$ :

BURGES < fr. bourgeois 15 .

«Llevaronme medio en peso, adonde dormi la pendencia, dexando à el pobre burges sin dormir de puro desvelado" (pág. 198).

BURGESIA $<$ fr. bourgeoisie.

"Iva yo muy triste, porque me avian informado entre otras cosas, no ser bueno aquel pais para mis mercancias, por la sutileza de ingenio, y gran trato de su burgesia;" (pág. 170).

CIRCUMVALACION $<\mathrm{fr}$. circonvallation.

"El replicò, que su ingenio no era de açucar, sino de hazer fortificaciones, i que aviendo visto, que la de su castillo estava errada, segun las reglas de Euclides, i que no sabrian los soldados, por ser bisoños, hazer circumvalacion, ni abrir ramal de trinchea, por eso...» (pág. 341).

CONVOY < fr. convoi (convoy).

"(...) le pedì à un Capitan conocido mio una carreta prestada, diziendole, no ser mas que para un comboy: $\mathrm{i}$ of reciendome al buen tratamiento del cavallo, con la qual, i el carro que llevava, me hize vivandero de verdad, aviendolo sido hasta allì de mentiran (pág. 175).

CONVOYAR $<\mathrm{fr}$. convoyer.

"(...) y clesde alli llegámos à Iulies, adonde Su Alteza Serenissima, accompañado de la cavalleria de Flandes, que le avia salido à recebir y convoyar, se apartò del exercito y se fue à dar alegrias à la grandiosa corte de Bruselas, que por instantes le estavan esperando» (pág. 163).

14 En La lengua española en Flandes..., hemos dedicado sendos capítulos a los préstamos burgés (págs. 68-77), burgesía (págs. 77-80), convoy-convoyar (págs. 81-88), reculta/recluta (págs. 138-148) y víveres (págs. 174-182).

15 En las páginas 68-77 de nuestro libro demostramos que la voz burges (burzes, burgues), que existe en el español medieval, dejó de usarse a partir de mediados del siglo xv. Volvió a surgir a finales del siglo XVI, pero únicamente en el español de Flandes, como voz nueva tomada del francés bourgeois. Se siguió usando en esta región a lo largo del siglo Xvir, pero no logró trasplantarse de alli a la Península. La voz burg(u)és que vuelve a surgir en la Península en 1722 es el resultado de un préstamo nuevo del francés de Francia, como lo confirma el comentario que hace el Diccionario de Autoridades sobre la voz burges: «BURGES: El vecino o natural de alguna villa o ciudad. Es voz tomada y de poco tiempo acá introducida del francés Bourgeois, que significa esto mismo...» (t. I, 1726, pág. 716). 
PATRULLA < fr. patrouille.

«Fuymonos a la posada, hallámos la abastecida de pavos de Indias, que avia traïdo otra patrulla que avia salido del mismo quartel» (pág. 75).

PLENIPOTENCIARIO < fr. plénipotentiaire.

«... fui à besar la mano à el Marques de Castel Rodrigo, que estava por Embaxador Ordinario de la Catholica i real Magestad, i por su primer Plenipotenciario para el tratado de las pazes: (pág. 265).

RECULTA metátesis de recluta < picardo recrute.

«Viendome cargado de tantos emulos, tratè (...) de hazer reculta de doblones...» (pág. 227).

TREN $<$ fr. train.

«... i para llevar mas tren i ostentacion, le pedì à un Capitan conocido mio una carreta prestada, diziendole, no ser mas que para un comboy: (página 174).

VIVERES $<$ fr. vivres.

«(...) me hizo vivandero de su compañia, dandome carro, cavallos, i dineros debaxo de palabra de prestamo, i con clausula, de darle los viveres necessarios à su casa al mismo precio que yo los comprasse en las villas (...)» (pág. 173).

A pesar de ser muchas de ellas corrientes en la lengua de hoy, eran todas voces desconocidas en el español peninsular o común de la primera mitad del siglo xVII. Ahora bien, estas voces se hallan en el Estebanillo, y las hemos encontrado frecuentemente en otros muchos textos que fueron escritos o publicados en Flandes a finales del siglo XVI y primera parte del XVII ${ }^{16}$. También se tomaron prestadas de la lengua francesa que - como es sabido- se hablaba en toda la parte meridional de los Países Bajos españoles y que, en la parte septentrional del país, era utilizada por las clases altas, además del neerlandés.

La existencia y la difusión de estos "préstamos» en un momento (primera mitad del siglo xVII y aun antes) en que éstos se desconocen en el español de la Península, nos inducen a preguntarnos si, en cuanto al léxico se refiere, el español de Flandes no tendría que considerarse como un área lingüística distinta de la del español peninsular.

Esta parece haber sido la impresión de algunos contemporáneos. Entre los varios testimonios que existen, nos limitamos a citar uno que proviene de la comedia Mentir y mudarse a un tiempo, escrita hacia 1650 por los hermanos Diego y José de Figueroa y Córdoba. En esta comedia

16 Véase la nota 14. 
los autores ponen en boca de un soldado español que vuelve de Flandes los versos siguientes:

\author{
No huvo mas lugar en Flandes, \\ que de aprender el lenguaje \\ del Pais, y el que la guerra \\ en sus terminos encierra, \\ llamando al hurtar pillaje; \\ à la presa, contradique; \\ à la manteca, buturo; \\ à la almena, casamuro; \\ à los Lugares, Mastrique; \\ Bulburque, Brujas, Dunquerque, \\ Lobayna, Ostende, Malinas; \\ à las montañas, colinas, \\ à las tapias, onaberque ${ }^{17}$.
}

Cabe preguntarse ahora cuál ha sido la suerte de estos "préstamos" peculiares del español de Flandes. Se pueden distinguir dos grupos:

Por un lado, una parte de estos "préstamos» se integró en el español general a lo largo de la segunda mitad del siglo xvII, como por ejemplo: circunvalación, convoy, convoyar, plenipotenciario, recluta, tren y viveres. ¿Cómo se realizó esta integración? ¿Quién o qué desempeñó el papel de "agente transmisor» entre el área española de Flandes y la de la Península? Creemos que, en la práctica, esta transmisión se ha realizado por distintas vías de penetración.

Los militares españoles que han combatido en Flandes, a veces durante largos años, y cuya lengua está "contaminada» por los muchos "préstamos» del español que se hablaba allí, al regresar a España, siguen utilizándolos no sólo oralmente, sino también en sus escritos. En efecto, les gusta publicar crónicas y memorias sobre los acontecimientos bélicos y políticos que han vivido en Flandes, y estos escritos tienen gran éxito en la Península ${ }^{18}$.

Otros españoles publican en los mismos Países Bajos sus escritos, que son difundidos e incluso reimpresos en la Península. Dos ejemplos: Las guerras de los Estados Baxos de Carlos Coloma, libro publicado por primera vez en Amberes en 1625, se vuelve a imprimir en Barcelona en 1627. Igual ocurre con la Vida y Hechos de Estebanillo González, pu-

17 Citado por Herrero Garcfa, M., Ideas de los españoles del siglo XVII, Madrid, 1966, pág. 429. Este transcribe el texto según la edición de la BAE, t. XLVII, pág. 403, que moderniza la grafía. Nosotros citamos según una edición más fidedigna (Madrid, A. Sanz, 1746, pág. 2).

18 Véase la nota 12. 
blicada por primera vez en Amberes en 1646, y que se vuelve a imprimir en Madrid en 1652 y 1655.

La correspondencia entre Bruselas y Madrid constituye otra vía de penetración. Las cartas enviadas por los jefes militares españoles a la Corte de Madrid son muy abundantes y contienen informes sobre la situación política y militar en Flandes.

Por otro lado, hay otros "préstamos» del español de Flandes que no lograron trasplantarse al español peninsular y que sólo se emplearon en Flandes mientras duró allí la dominación española. Por ejemplo: brandevín, caramesa, liarte, maltota, metresa, ranç(i)ón. En esta categoría entran también palabras como burgés, burgesía y patrulla que tampoco se integraron al español común durante la dominación española en Flandes. Su presencia en la lengua española actual es la consecuencia de la influencia directa del idioma francés a lo largo de los siglos siguientes [burg $(u) e ́ s$ y patrulla en el siglo xvirr; burguesía en el siglo XIX] ${ }^{19}$.

Creemos que los elementos que acabamos de exponer nos permiten deducir tres conclusiones que esbozamos a continuación.

En primer lugar, gran parte de las voces del Estebanillo que los especialistas han tildado de "extranjerismos» y "galicismos» no son voces raras ni constituyen el resultado de interferencias léxicas aisladas. Trascienden el idiolecto del autor. Igual que otras muchas, como burgés, burguesia, convoy, convoyar, patrulla, recluta, tren, viveres, etc. -en las que los especialistas dejaron de reparar- eran voces desconocidas en el español común, pero frecuentemente utilizadas en el español de Flandes. Se trata de "préstamos» tomados del francés (picardo, valón), que se hablaba en los Países Bajos meridionales. Estos "préstamos» formaban una parte integrante del español hablado y escrito en los Estados de Flandes. Por lo tanto, es normal que también los haya utilizado el autor de la novela picaresca Vida y hechos de Estebanillo González, quien pasó varios años de su agitada vida en los Países Bajos españoles, e incluso redactó allí mismo su novela. Era, por tanto, un autor que había asimilado gran parte de las peculiaridades léxicas de la lengua española de Flandes.

En segundo lugar, como es sabido, el Estebanillo y los libros de otros españoles de Flandes han servido a varios lexicógrafos y etimologistas como fuente para documentar, fechar e ilustrar varias voces del español. Éstos han considerado el testimonio de un vocablo en tales libros como la prueba de la existencia de dicho vocablo en el español

19 Remitimos a nuestras publicaciones mencionadas en las notas 9 y 13. 
común de la primera mitad del siglo xviI. Ahora bien, nuestras investigaciones han probado que nada es menos cierto: existen en el área española de Flandes toda una serie de vocablos, tomados de las lenguas autóctonas - sobre todo el francés (picardo, valón)- que en aquel entonces se desconocen en el área peninsular. Por tanto, proponemos que en adelante se excluya a estos autores como fuente para documentar la existencia, la fechación y el significado de voces en el español general ${ }^{20}$. Los préstamos contenidos en los textos españoles de Flandes deben entrar en un futuro "Diccionario de la lengua española de Flandes» ${ }^{21}$.

Un tercer elemento nuevo que nuestras investigaciones han permitido descubrir es que, gracias a los contactos permanentes entre Flandes y España (trasiego de escritos y de hombres), varios "préstamos» pasan a la Península, y logran imponerse en el siglo xviI. La mayor parte de ellos se sigue utilizando en el español de hoy. Se puede afirmar que entre otros muchos textos procedentes de Flandes, el Estebanillo contribuyó, gracias a sus ediciones madrileñas de 1652 y 1655, a la difusión de estos "préstamos" de Flandes en el español general.

Sugerimos que en adelante los diccionarios históricos y etimológicos proporcionen en cada uno de estos casos dos fechas de primera aparición: el primer testimonio de la voz en los textos de los españoles que estuvieron en Flandes, y luego el primer testimonio de la voz en los autores españoles de la Península que no tuvieron contactos directos con aquella posesión de la Corona.

\section{ROBERT A. VERDONK}

20 A no ser - claro está- que estén atestiguadas con la misma acepción en autores peninsulares de la misma época.

21 Nos estamos aplicando a la faena de su redacción. Como un trabajo de tal envergadura requiere necesariamente la colaboración de todos (filólogos e historiadores), agradecemos toda sugerencia que nos permita conocer la difusión exacta de cada préstamo.

LXVI, $1.0-2.0-8$ 